\title{
An Overview on Application of Exergy and Energy for Determination of Solar Drying Efficiency
}

\author{
Lyes Bennamoun
}

Department of Applied Chemistry, University of Liège, Sart Tilman Bât. 6c, Liège, 4000, Belgium

\begin{abstract}
The main objective of this work is to give an overview of the different used mathematical methods for modeling and calculating the energy and exergy efficiency of a solar dry ing system. For determination of the energy efficiency of thin or thick layers, heat and mass balances are established to the different components. In the case of thick layers equations of porous media are used. These methods allow following, in particular, the variations of the heated air and the product temperature and humidity. As a second part, the common way for the calculus of the exergetic efficiency passes through the establishment of exergy balance and after calculating the input, output and exergy loss. The influence and illustration of several parameters are as well presented in this paper.
\end{abstract}

Keywords Solar Air Collector, Drying Chamber, Energetic Efficiency, Exergy Efficiency, Mathematical Modelling

\section{Introduction}

Drying constitutes an important process for a large variety of industries. For example, for foodstuffs, it is a necessary step for the preservation of the final product or to make it ready to be stored[1-4]. On the other hand and for other materials, such as woods, concretes, bricks and sludge, the passage by this process is an obligation to make these products marketable[5-8]. As it is well known, drying is the most energy intensive operation of the industrial processes. In most industrialized countries, between 7 and $15 \%$ of a nation's industrial energy is used for drying[9]. Other estimations report that national energy consumption for industrial drying operations are ranging from 10 to $15 \%$ for United States, Canada, France and United Kingdom and reach 20 to $25 \%$ for Denmark and Germany[10]. Furthermore, around $35 \%$ of the consumed energy in drying is used for paper and pulp industry and only $5 \%$ are used for chemicals [10]. The resulted high cost of this unit operation directed the efforts of the Scientifics to look for alternative cheap sources of energy, in particular free solar energy. Coupling the two ideas gives birth to several types of solar dryers. In general manner, solar dryers are classified into active and passive dryers and each classification is divided into direct, indirect and mixed mode type[11-13]. However and in order to face the intermittent character of solar energy, developed systems can be dotted with a second source of energy using

* Corresponding author:

Lyes.Bennamoun@ulg.ac.be (Lyes Bennamoun)

Published online at http://journal.sapub.org/ijee

Copyright (C 2012 Scientific \& Academic Publishing. All Rights Reserved electrical heater[1, 14] or storage systemsfilled with packed rock-beds [15-17], gravels [18], desiccants [19], water[20] or phase change material[21-23]. We cannot have an optimum use and design of a solar dryer without passing through simulation and the mathematical modelling. The existing models are taking essentially two ways: the first approach studies particularly the behaviour of the product during the process represented by the drying kinetic. These developed models agree to calculate several parameters such as coefficient of diffusion, heat and mass coefficients and drying constants [5, 24-35]. The second approach studies the general behaviour of the solar dryer by applying heat and mass transfers. It allows following variations of temperature and humidity of both the dried product and the heated air. But also it permits following the different temperatures and other parameters of the solar collector and the drying chamber. By this method, efficiency of the studied system can be easily obtained. In this paper, we are focusing on this second approach.

In this last decade, exergy is introduced as an important and a powerful analysis tool for design and calculus of the performances of thermal systems. From a thermodynamic point of view, exergy is defined as the maximu m amount of work which can be produced by a quantity or flow of matter, heat or work as it comes to equilibrium with a reference environment[36]. Exergy starts finding applications in several industries and we direct our attention to the application for drying process [37-44].

Therefore, the aim of this paper is to present a review about the application of exergy and energy to solar drying with presentation of the different mathematical models that treat the general behaviour of the drying systems and calculate their energetic and exergetic efficiencies with 
products packed in thin or thick layers.

\section{Energy Analysis}

\subsection{Solar Drying of Thin Layers}

We will apply our study to a representative simple convective solar dryer, represented in Figure 1a. It is constituted of two parts; a simple flat solar air collector (Figure 1b). It is composed of an aluminium plate used as an absorber, covered from the above by a glass plate and insulated from the exterior using polystyrene. There is a vacuum space between the absorber and the glass cover. The second part concerns the drying chamber made with bricks insulated from the exterior by polystyrene and can support trays where the product is putted. Forced convection is obtained using a fan which permits to have a homogeneous distribution of the heated air inside the drying chamber; also it allows having better control of the process [1,11].

One of the frequent models used to study solar drying of thin layers (putted in perforated trays), is: step by step method[1, 13,45]. It consists on taking a fictitious slice that can be noted " $\mathrm{j}$ ", apply ing heat and mass balance to this slice, then generalizing the study to all the system by varying the step " $\mathrm{j}$ ". This method is applied to both the solar collector (Figure 1b) and the drying chamber (Figure 2).

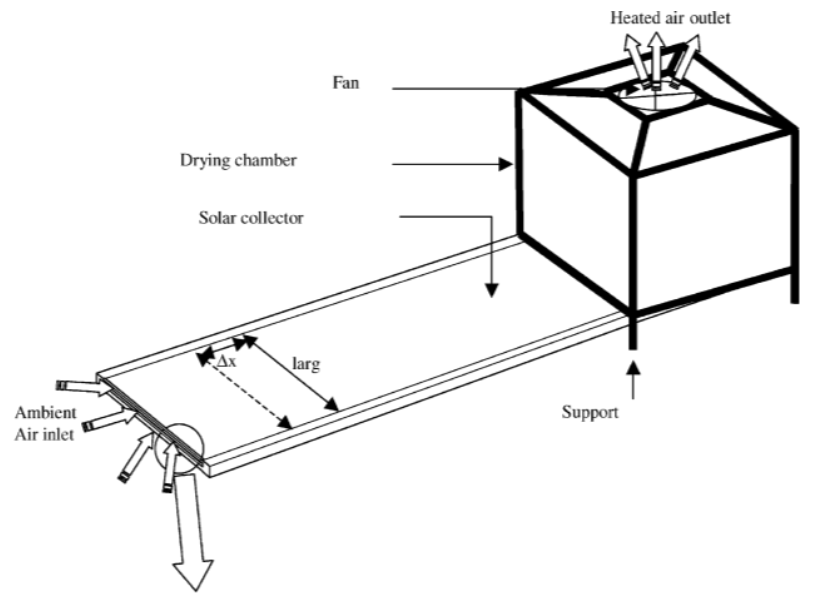

(a)

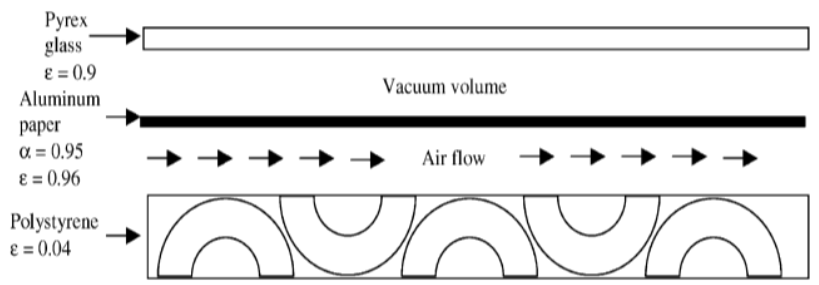

(b)

Figure 1. (a) Global diagram of a solar dryer. (b) Step " $j$ " of the flat plate solar air collector[1]

\subsubsection{Application to the Solar Collector}

A heat balance is established for the different components; which are the interior and exterior side of the glass cover, the absorber, the interior and exterior side of the insulator, resumed by Equation 1 and Table 1:

Table 1. Definitions and values of the different used indices and parameters at application of heat balance to different components of the solar collector

\begin{tabular}{|c|c|c|}
\hline $\mathrm{n}^{\circ}$ & Part of application & Definitions and values \\
\hline 1 & Glass exterior side & $\begin{array}{c}\text { i: glass exterior side } \\
\text { j: skier vault } \\
\text { k: ambient environment } \\
\text { l: glass interior side } \\
\mathrm{q}_{1} \text { : flux of energy stored by the } \\
\text { glass } \\
\mathrm{q}_{2}=\mathrm{q}_{3}=0\end{array}$ \\
\hline 2 & Glass Interior side & $\begin{array}{l}\text { i: glass interior side } \\
\mathrm{j} \text { and } \mathrm{k} \text { : absorber } \\
\text { 1: glass exterior side } \\
\mathrm{q}_{1}=\mathrm{q}_{2}=\mathrm{q}_{3}=0 \\
\end{array}$ \\
\hline 3 & Absorber & $\begin{array}{c}\text { i: glass interior side } \\
\mathrm{j} \text { and } \mathrm{k} \text { : absorber } \\
\mathrm{k}_{\mathrm{i}, \mathrm{l}}=0 \\
\mathrm{q}_{1} \text { : flux of energy absorbed by the } \\
\text { absorber } \\
\mathrm{q}_{2}=\mathrm{h}_{\text {fld, }}\left(\mathrm{T}^{*}-\mathrm{T}_{\mathrm{A}}\right) \text {; exchange by } \\
\text { convect ion bet ween the absorber } \\
\text { and the heated air } \\
\mathrm{q}_{3}=\mathrm{hr}_{\mathrm{L}, \mathrm{A}}\left(\mathrm{T}_{\mathrm{Li}}-\mathrm{T}_{\mathrm{A}}\right) \text {; exchange by } \\
\text { radiation bet ween the absorber } \\
\text { and the interior side of the } \\
\text { insulat or }\end{array}$ \\
\hline 4 & Insulator interior side & $\begin{array}{l}\text { i: interior side of the insulat or } \\
\text { j: absorber } \\
\text { k: heated air } \\
\text { l: exterior side of the insulator } \\
\quad \mathrm{q}_{1}=\mathrm{q}_{2}=\mathrm{q}_{3}=0\end{array}$ \\
\hline 5 & Insulator exterior side & $\begin{array}{l}\text { i: exterior side of the insulator } \\
\text { j: ground } \\
\text { k: ambient environment } \\
\text { l: interior side of the insulat or } \\
\quad \mathrm{q}_{1}=\mathrm{q}_{2}=\mathrm{q}_{3}=0\end{array}$ \\
\hline
\end{tabular}

Also, the air flowing between the absorber and the insulator is written in the following form:

$$
\begin{array}{r}
\dot{m}_{\text {am }} \cdot C p_{\text {air }}\left(T-T^{*}\right) \\
=\operatorname{surf} \cdot h_{\text {air }, A} \cdot\left(T_{A}-T^{*}\right) \\
+\operatorname{surf} \cdot h_{\text {air }, I} \cdot\left(T_{I, \text { int }}-T^{*}\right)
\end{array}
$$

The resolution of the obtained system composed of six diffe rential equations, using any adapted method such as the iterative method of Gauss-Seidel[1], allows calculating the temperature of exit fro $m$ the solar collector, necessary for the calculus of its efficiency.

The efficiency of a solar collector is generally calculated using the subsequent equation[46-49]:

$$
\eta=\frac{\dot{m} C p \int_{t 1}^{t 2}\left(T_{o}-T_{i}\right) d t}{A_{c} \int_{t 1}^{t 2} I_{t} d t}
$$

transformed by Hottel-Whiller-Bliss, for the steady state case and rewritten in the following form: 


$$
\eta=\frac{Q_{u}}{A_{c} I_{t}}=F_{R}(\tau \alpha)-F_{R} U_{L} \frac{T_{i}-T_{\alpha}}{I_{T}}
$$

Where:

$F_{R}$ is the heat removal factor of solar collector, calculated:

$$
F_{R}=\frac{\dot{m} C p}{A_{c} U_{L}}\left(1-\exp \left(A_{c} U_{L} F^{\prime} / \dot{m} C p\right)\right.
$$

And:

$\mathrm{U}_{\mathrm{L}}$ is the global heat loss coefficient, written:

$$
U_{L}=\frac{I_{t h}(\tau \alpha)}{\left(T_{i}-T_{o}\right)}
$$

This approach is widely used for experimental works as it needs to know only geometric parameters of the solar collector and just inlet and outlet temperatures which can be easily obtained using thermocouples.

Studies have shown that performances of a solar collector, represented by its outlet air temperature and its efficiency, depend on several parameters like the region where the collector is installed [45], depend on their internal parameters, such as its surface (Figure 2) and the exterior conditions like the temperature and the velocity of the ambient air[35, 45]. These performances vary with time and have a general behavior as the total received radiations (Figure 2).

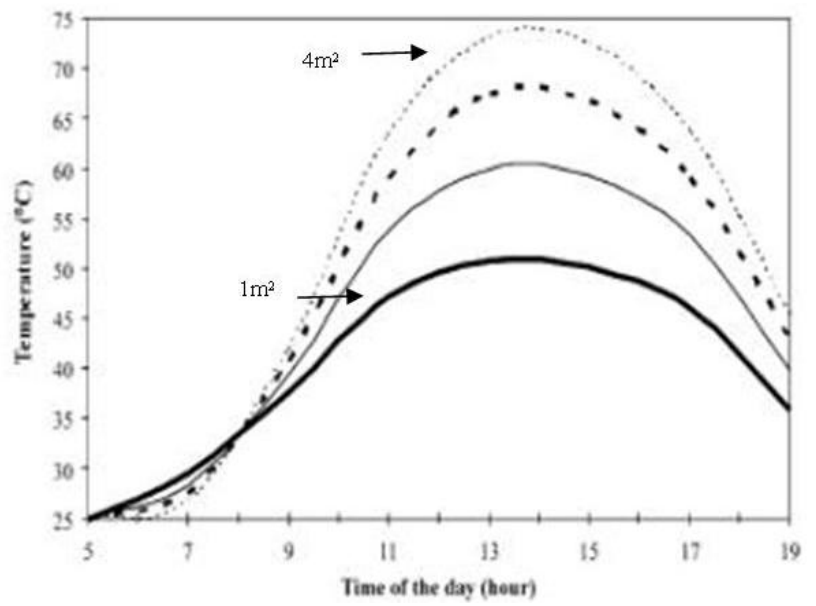

Figure 2. Influence of the surface of the collector on its outlet air temperat ure[1]

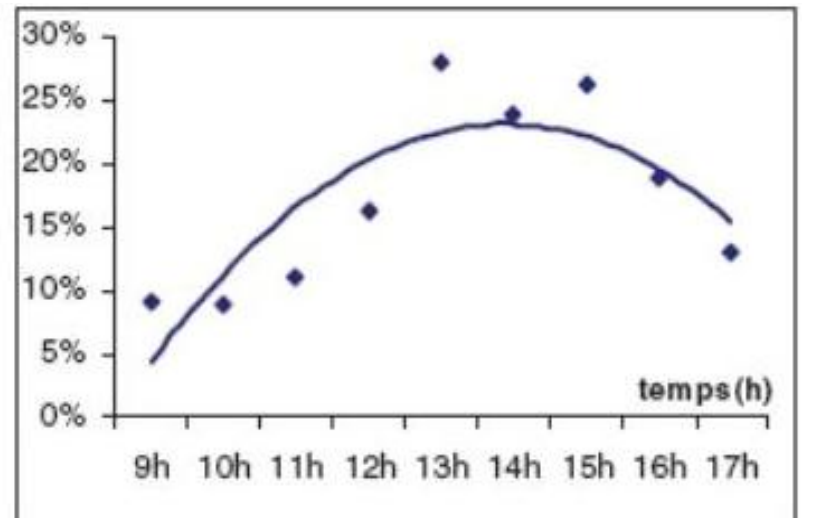

Figure 3. Variation of the efficiency of a solar collector with time[48]

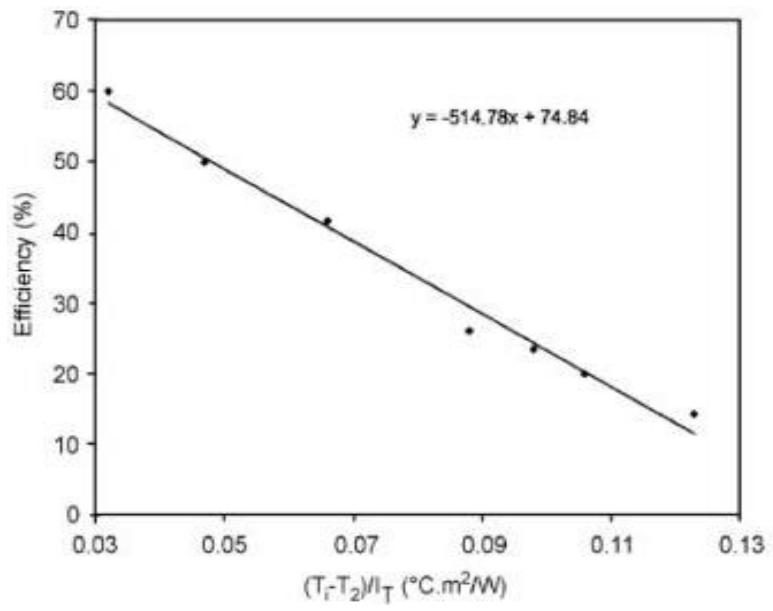

Figure 4. Collect or efficiency with $\left(\mathrm{T}_{\mathrm{i}} \mathrm{T}_{\mathrm{a}}\right) / \mathrm{I}_{\mathrm{T}}[46]$

Consequently, the efficiency of a solar collector varies in time (Figure 3) and depends strongly on the absorbed radiations and collector outlet temperature (Figure 4). The values of the efficiency are variable and can reach $60 \%$.

\subsubsection{Application to the Dry ing Chamber}

A step “ $\mathrm{j}$ ” of the drying chamber is shown in Figure 5.

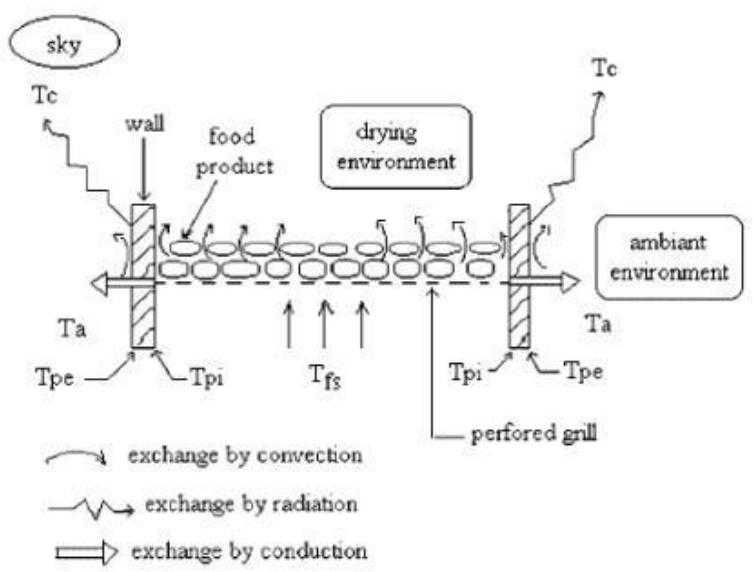

Figure 5. Step “j” of the drying chamber[50]

Heat balance is established between the heated air, the product and the interior face of the brick wall leading to:

$$
\begin{array}{r}
\dot{m}_{\text {ach }} \cdot C p_{\text {air }}\left(T^{*}{ }_{a c h}-T_{a c h}\right) \\
=h_{a c h, f} S_{f} \cdot\left(T_{a c h}-T_{f}\right) \\
+h_{a c h, p i} S \cdot\left(T_{a c h}-T_{p i}\right)
\end{array}
$$

$\mathrm{S}_{\mathrm{f}}$ represents the exchange surface between the total surface of the product and the air. It is given as a function of the dimensions of the product and its number[1, 13].

The other exchanges can be represented by the next equation and table 2.

$$
\frac{m_{i} C p_{i}}{S}\left(\frac{d T_{i}}{d t}\right)=h r_{i, j}\left(T_{j}-T_{i}\right)+h_{i, k}\left(T_{k}-T_{i}\right)+k_{i, l}\left(T_{l}-T_{i}\right)+q
$$

However, the exchanges between the brick and the polystyrene wall are given by: 


$$
\begin{aligned}
& \frac{m_{p} C p_{p}}{S}\left(\frac{d T_{p}}{d t}\right)+k_{p}\left(T_{p}-T_{p e}\right) \\
& =\frac{m_{b} C p_{b}}{S}\left(\frac{d T_{p}}{d t}\right)+k_{b}\left(T_{p}-T_{p i}\right)
\end{aligned}
$$

Table 2. Definitions and values of the different used indices and parameters at application of heat balance to different components of the

\begin{tabular}{|c|c|c|}
\hline $\mathrm{n}^{\circ}$ & Part of application & Definitions and values \\
\hline 1 & Product & $\begin{array}{c}\text { i: product } \\
\mathrm{hr}_{\mathrm{ij}}=\mathrm{k}_{\mathrm{i} 1}=0 \\
\mathrm{k} \text { : heated air } \\
\mathrm{q}=-\mathrm{Pev}\end{array}$ \\
\hline 2 & $\begin{array}{l}\text { Internal Surface of the } \\
\text { brick wall }\end{array}$ & $\begin{array}{l}\text { i: brick interior side } \\
\quad \mathrm{hr}_{\mathrm{i}, \mathrm{j}}=0 \\
\mathrm{k} \text { : heated air } \\
\text { l: brick exterior side } \\
\mathrm{q}=0\end{array}$ \\
\hline 3 & Insulator exterior side & $\begin{array}{l}\text { i: exterior side of the insulator } \\
\text { j: skier vault } \\
\text { k: ambient air } \\
\text { l: interior side of the insulat or } \\
\quad \mathrm{q}=0\end{array}$ \\
\hline
\end{tabular}
drying chamber

Pev is the evaporative power given as a function of the mass and the drying kinetic of the studied product.

The resolution of this system of differential equations allows calculating the different changing parameters inside the drying chamber especially the variations of the temperatures of the product and the air for the several horizontal trays. By this method, drying chamber efficiency can be calculated, well known as pick up efficiency, written[51-53]:

$$
\eta=\frac{W}{\rho V t\left(h_{a s}-h_{i}\right)}
$$

This parameter determines the efficiency of moisture removal by the drying air from the product.

The obtained results, dealing with solar drying of multiple trays, show that the process is done with a non-homogeneous manner, as shown in Figure 6 and 7. The product putted in tray near the heating source dries faster than products putted in the other trays.

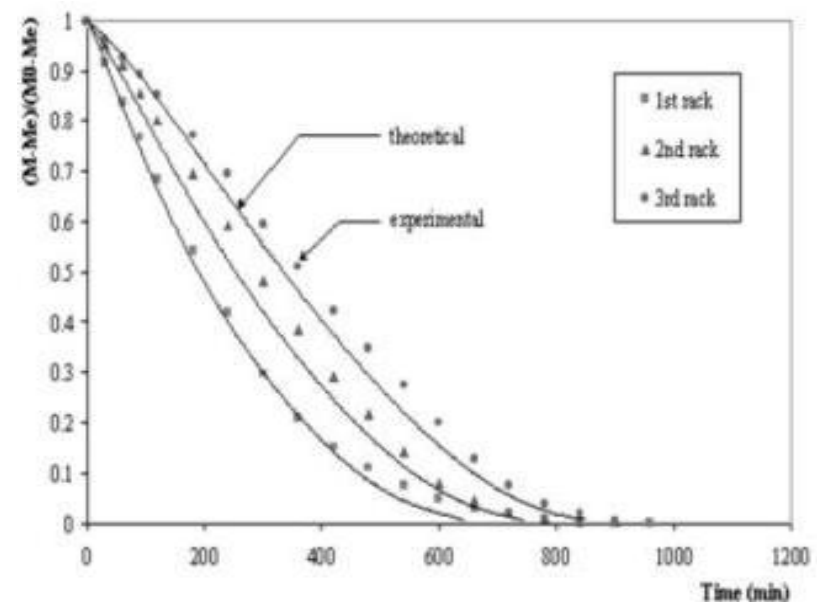

Figure 6. Evolution of the reduced content in three racks[50]

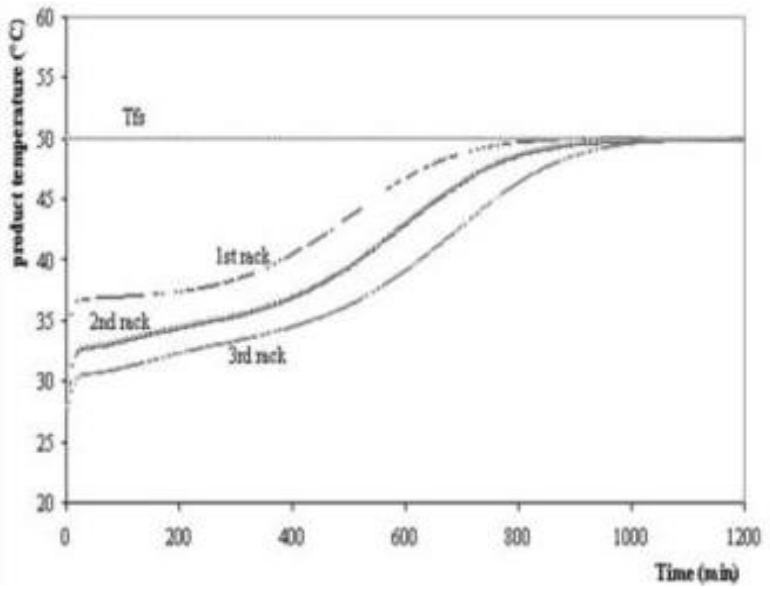

Figure 7. Product temperature profile[50]

Also some studies show that drying kinetics of the dried product and its temperature is affected[1]: by the surface of the solar collector, by the characteristic dimensions of the product, by the mass of the product putted on each tray and by the air flow rate[50].

\subsection{Solar Drying of Thick Layers}

The unique difference between solar drying of thin and thick layers is that, for the second case, the product is filled in multiple condensed layers. However, it does not affect the precedent study relative with the solar collector and the same mathe matical procedure is used.

As the product is filled in thick layers, the drying chamber can be supposed as a porous media in the macroscopic scale. So, mathematical model describing transfer in porous media can be applied for the product, represented by the solid phase, and the heated air, presented as the gas phase. We obtain four differential equations [4, 13, 51].

Application of mass balance in gas phase:

$$
\varepsilon \rho_{f} \frac{\partial w}{\partial t}+\rho_{f} \vec{V}_{f} \vec{\nabla} w-\rho_{f} D \nabla^{2} w=\sigma_{f}
$$

Mass balance in solid phase:

$$
(1-\varepsilon) \rho_{s} \frac{\partial C}{\partial t}+(1-\varepsilon) \rho_{s} \vec{V}_{s} \vec{\nabla} C=\sigma_{f}
$$

Heat balance in gas phase:

$$
\begin{aligned}
& {\left[(\rho C p)_{a p p}\right]_{f}\left(\varepsilon \frac{\partial T_{f}}{\partial t}+\vec{V}_{f} \vec{\nabla} T_{f}\right)-k \nabla^{2} T_{f}} \\
& =h A\left(T_{f}-T_{s}\right)
\end{aligned}
$$

Heat balance in solid phase:

$$
\begin{aligned}
& {\left[(\rho C p)_{a p p}\right]_{s}\left(\varepsilon \frac{\partial T_{s}}{\partial t}+\vec{V}_{s} \vec{\nabla} T_{s}\right)} \\
& =-h A\left(T_{s}-T_{f}\right)+H \rho_{s}(1-\varepsilon) \frac{\partial C}{\partial t}
\end{aligned}
$$

With:

$$
\sigma_{f}=-\sigma_{s}
$$

Combinations of equations 11 with 12 and 13 with 14 give: 


$$
\begin{gathered}
\varepsilon \frac{\partial w}{\partial t}+V_{f} \frac{\partial w}{\partial y}=D \frac{\partial^{2} w}{\partial y^{2}}-(1-\varepsilon) \frac{\rho_{s}}{\rho_{f}} \frac{\partial C}{\partial t} \\
(\rho C p)_{e f f} \frac{\partial T}{\partial t}+(\rho C p)_{f}\left[V_{f} \frac{\partial T}{\partial y}\right] \\
=k_{\text {eff }} \frac{\partial^{2} T}{\partial y^{2}}+H \rho_{s}(1-\varepsilon) \frac{\partial C}{\partial t}
\end{gathered}
$$

With:

$$
(\rho C p)_{e f f}=\varepsilon(\rho C p)_{f}+(1-\varepsilon)(\rho C p)_{s}
$$

These equations are obtained after considering the following simplifications[51]: the walls of the drying chamber are considered as adiabatic, the product is immobile and the is otropic. Also, we consider that the air is flowing in one direction. The resolution of the differential equation system permits following the variations of the temperature and humidity for both the product and the heated air with time and the deepness of the layers. In consequence, efficiency of the drying chamber can be easily calculated using equation $10[51]$.

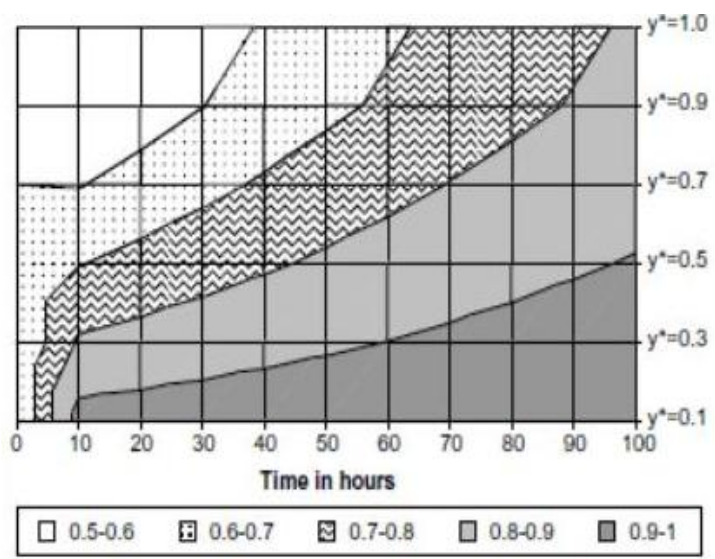

Figure 8. Variation of the temperature of the media vs. time and bed deep[51]

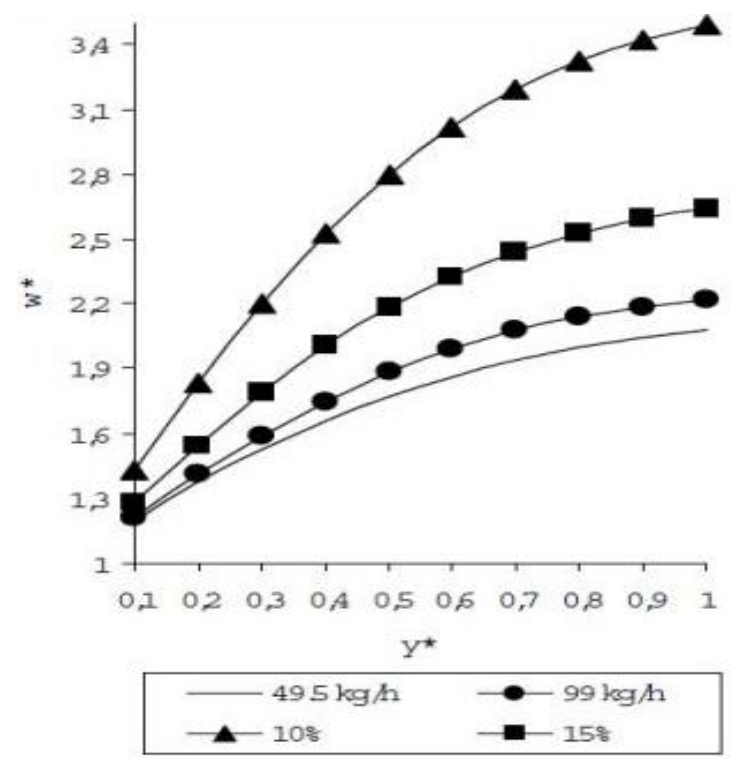

Figure 9. Influence of flow rate and initial humidity on humidity of the heated air[54]
Some studies have shown that thick layer drying is also done in a non-homogeneous manner. The temperature and drying kinetic was affected by many parameters, such as the initial humidity of the air, the flow rate and the height of the bed (Figure 8 and 9)[51, 54]. A representation of the efficiency is shown in Figure 10, with variation in time and height of the bed.

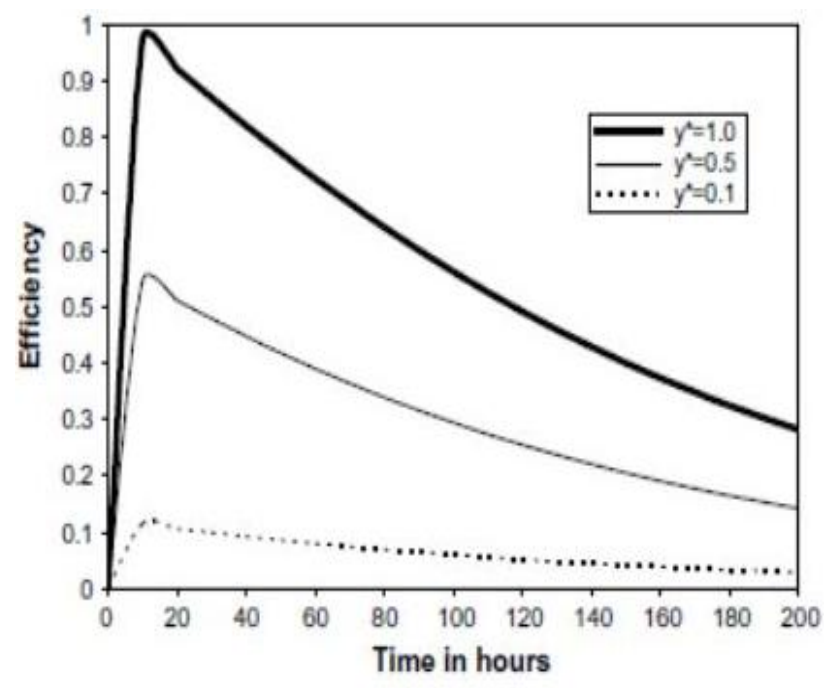

Figure 10. Variation of the pick-up efficiency during drying of thick layers[51]

\subsection{System Efficiency}

The system efficiency indicates the overall thermal performance of a dry ing system including the efficiency of a solar collector, the drying chamber and any other supplement add to the system. The global efficiency is written[52]:

For natural convection solar dryers:

$$
\eta=\frac{W L}{I A}
$$

For forced convection solar dryers that use a fan or a bowler:

$$
\eta=\frac{W L}{I A+P_{f}}
$$

For hybrid solar dryers that use a second source of energy, the efficiency is calculated using the next equation:

$$
\eta=\frac{W L}{I A+P_{f}+\left(m_{b} \times L C V\right)}
$$

It clear $\left(m_{b} * L C V\right)$ represents the additional source of energy.

\section{Exergy Analysis}

Exergy is presented as a useful analysis tool in the design, assessment, optimization and improvement of energy systems, that can be applied on both system and components levels [55-56]. The exergy method can help further the goal of more efficient energy resource use, because it enables the locations, types and true magnitudes of looses to be determined. As a result, exergy analysis can reveal where 
and by how much it is possible to design more efficient thermal systems by reducing the sources of existing inefficiencies [49].

The second law of thermodynamics introduces the useful concept of exergy in the analys is of thermal systems. Exergy analys is evaluates the available energy at different points in a system. Exergy is a measure of the quality of grade of energy and it can be destroyed in the thermal system. The second law states that part of the exergy entering a thermal system with fuel, electricity, flowing streams of matter, and so on is destroyed within the system due to irreversibility. The second law of thermodynamics uses an exergy balance for the analysis and the design of thermal systems [49].

The general mathematical description of the exergy is presented under the following equation [48-49, 57-59]:

$$
\begin{aligned}
& \text { Exergy }=\left(u_{0}-u_{m}\right)-T_{m}\left(s-s_{m}\right) N+\frac{P_{m}}{J}\left(v_{0}-v_{m}\right)+\frac{v^{2}}{2 g J} \\
& +\left(z-z_{0}\right) \frac{g}{g J}+\sum_{c}\left(\mu_{c}-\mu_{m}\right) N_{c}+E_{i} A_{i} F_{i}\left(3 T^{4}-T_{m}^{4}-4 T_{m} T^{3}\right)
\end{aligned}
$$

Where: $\infty$ represents the reference conditions.

The right terms of the equations are respectively: internal energy, entropy, work, momentum, gravity, chemical reactions and radiation emission.

One of the common simplifications used for equation 22 is to substitute enthalpy for the internal energy and PV. Also, the exergy is used with neglecting gravitational and momentum terms. The pressure term is neglected because the volume is almost kept constant and the operation is happening without any chemical reactions. Consequently, the equation is generally reduced to:

$$
\text { Exergy }=m_{a} C p_{a}\left[\left(T-T_{\infty}\right)-T_{\infty} \ln \frac{T}{T_{\infty}}\right]
$$

\subsection{Application of Exergy for Solar Collector}

The most presented papers, dealing with exergy analysis of solar drying, are presenting solar dryers similar to one illustrated in Figure 1. The drying system contains a simple solar air heater, and a drying chamber that supports horizontal trays. The system can work with natural convection (without fan) or using forced convection (with fan).

In the case of application of exergy to a simple solar air collector; the terms of momentum, gravity and chemical reaction can be neglected. However, rad iation e mission term that depends on temperature must be kept.

The exegy loss is the difference between the exergy in let and outlet that are respectively functions of the in let and outlet temperatures. It is expressed:

Exergy loss = Exergy inflow-exergy outflow

Mathematically determined by equation 24 :

$$
\sum E x_{l}=\sum E x_{i}-\sum E x_{o}
$$

The exergy in let for the collector is stated as equation 25 .

$$
E x_{c i}=m_{c a i} C p_{a}\left[\left(T_{c i}-T_{\infty}\right)-T_{\infty} \ln \frac{T_{c i}}{T_{\infty}}\right]
$$

And the exergy outlet for the collector is written:

$$
E x_{c o}=m_{c a o} C p_{a}\left[\left(T_{c o}-T_{\infty}\right)-T_{\infty} \ln \frac{T_{c o}}{T_{\infty}}\right]
$$

Then the exergy of solar radiation for the collector:

$$
E x_{\text {solar }}=E_{n e t}\left[1-\frac{4 T_{0}}{3 T}+\frac{1}{3}\left(\frac{T_{0}^{4}}{T}\right)\right] A_{c z}
$$

The exergy efficiency of a solar collector is:

$\operatorname{Ex}($ efficiency $)=(\operatorname{Ex}($ inflow $)-\operatorname{Ex}(\operatorname{los} s)) / E x($ inflow $)$

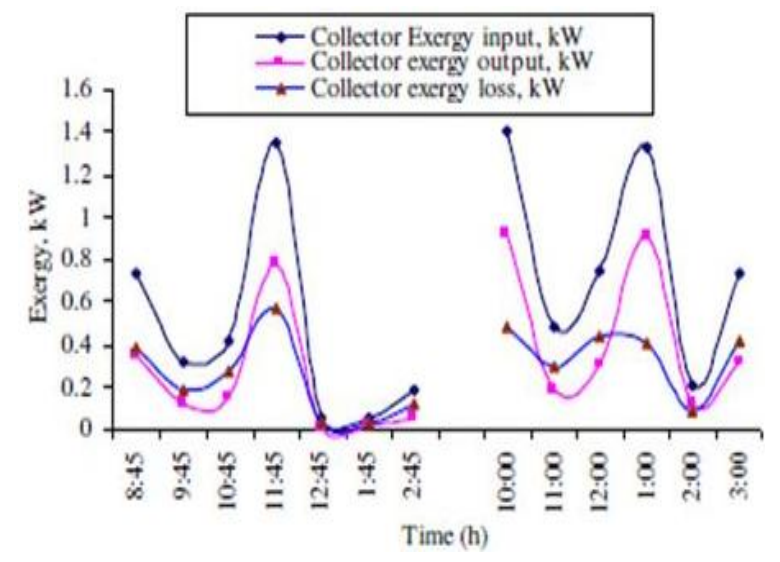

Figure 11. Variation of the collector exergy parameters with drying time[49]

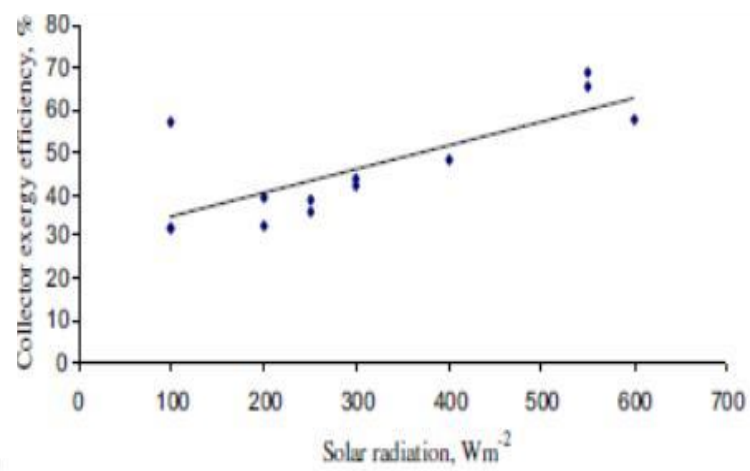

Figure 12. Variation of the collector exergy efficiency parameters with solar radiation [49]

Figure 11 shows the variations of the input, output and loss exergy for a solar collector with drying time. The general outline of the curves in influenced by the variation of the received solar radiation as they have almost the same appearance. Of course, the efficiency of the solar collector decreases with the solar radiation decrease, as shown in Figure 12.

\subsection{Application of Exergy to the Drying Chamber}

Based on the same way, a comprehensive procedure of the application of exergy for the drying chamber was developed[36, 60-61]. A representative scheme is illustrated in Figure 13. 


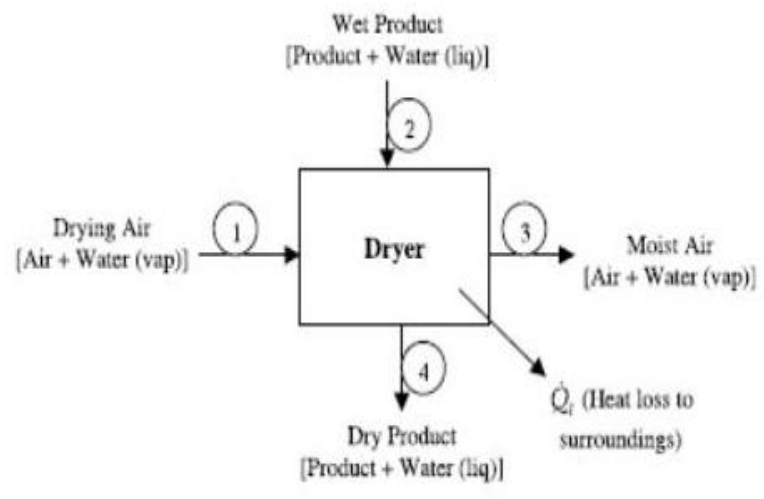

Figure 13. Schematic of a drying process showing input and output terms for the drying chamber[60-61] Exergy balance gives[60-61]:

Exergy balance gives:

$$
\begin{aligned}
& \dot{m}_{a} e_{1}+\dot{m}_{p}\left(e_{p}\right)_{2}+\left(\dot{m}_{w}\right)_{2}\left(e_{w}\right)_{2} \\
& =\dot{m}_{a} e_{3}+\dot{m}_{p}\left(e_{p}\right)_{4}+\left(\dot{m}_{w}\right)_{4}\left(e_{w}\right)_{4}+\dot{E}_{q}+\dot{E}_{d}
\end{aligned}
$$

With:

$$
\begin{aligned}
e_{1}= & {\left[\left(C_{p}\right)_{a}+\omega_{1}\left(C_{p}\right)_{v}\right]\left(T_{1}-T_{0}\right) } \\
- & T_{0}\left\{\left[\left(C_{p}\right)_{a}+\omega_{1}\left(C_{p}\right)_{v}\right] \ln \left(\frac{T_{1}}{T_{0}}\right)-\left(R_{a}+\omega_{1} R_{v}\right) \ln \left(\frac{P_{1}}{P_{0}}\right)\right\} \\
+ & \mathrm{T}_{0}\left\{\left(R_{a}+\omega_{1} R_{v}\right) \ln \left(\frac{1+1.6078 \omega^{0}}{1+1.6078 \omega_{1}}\right)+1.6078 \omega_{1} R_{a} \ln \left(\frac{\omega_{1}}{\omega^{0}}\right)\right\} \\
e_{3}= & {\left[\left(C_{p}\right)_{a}+\omega_{3}\left(C_{p}\right)_{v}\right]\left(T_{3}-T_{0}\right) } \\
& -T_{0}\left\{\left[\left(C_{p}\right)_{a}+\omega_{3}\left(C_{p}\right)_{v}\right] \ln \left(\frac{T_{3}}{T_{0}}\right)-\left(R_{a}+\omega_{3} R_{v}\right) \ln \left(\frac{P_{3}}{P_{0}}\right)\right\} \\
& +\mathrm{T}_{0}\left\{\left(R_{a}+\omega_{3} R_{v}\right) \ln \left(\frac{1+1.6078 \omega^{0}}{1+1.6078 \omega_{3}}\right)+1.6078 \omega_{3} R_{a} \ln \left(\frac{\omega_{3}}{\omega^{0}}\right)\right\}
\end{aligned}
$$

Also we have:

$$
\begin{aligned}
e_{p}= & {\left[h_{p}(T, P)-h_{p}\left(T_{0}, P_{0}\right)\right]-T_{0}\left[s_{p}(T, P)-s_{p}\left(T_{0}, P_{0}\right)\right] } \\
e_{w}= & {\left[h_{f}(T)-h_{g}\left(T_{0}\right)\right]+v_{f}\left[P-P_{g}(T)\right] } \\
& -T_{0}\left[s_{f}(T)-s_{g}\left(T_{0}\right)\right]+T_{0} R_{v} \ln \left[\frac{P_{g}\left(T_{0}\right)}{x_{v}^{0} P_{0}}\right] \\
\dot{E}_{q}= & \dot{m}_{a} e_{q}=\dot{m}_{a}\left(1-\frac{T_{0}}{T_{a v}}\right) q_{1}=\left(1-\frac{T_{0}}{T_{a v}}\right) Q_{1}
\end{aligned}
$$

On the other hand, the exergy efficiency is presented as: $\eta_{\mathrm{ex}}=$ Exergy for evaporation of moisture in product $/$ Exergy of dry ing air supplied

Or mathematically:

$$
\eta_{e x}=\frac{\left(\dot{m}_{w}\right)_{e v}\left[\left(e_{w}\right)_{3}-\left(e_{w}\right)_{2}\right]}{\dot{m}_{a} e_{1}}
$$

Where:

$$
\begin{gathered}
\left(\dot{m}_{w}\right)_{e v}=\left(\dot{m}_{w}\right)_{2}-\left(\dot{m}_{w}\right)_{4} \\
\left(e_{w}\right)_{3}=\left[h\left(T_{3}, P_{v 3}\right)-h_{g}\left(T_{0}\right)\right] \\
-T_{0}\left[s\left(T_{3}, P_{v 3}\right)-s_{g}\left(T_{0}\right)\right]+T_{0} R_{v} \ln \left[\frac{P_{g}\left(T_{0}\right)}{x_{v}^{0} P_{0}}\right] \\
\mathrm{P}_{\mathrm{v} 3}=\left(\mathrm{x}_{v}\right)_{3} \mathrm{P}_{3}
\end{gathered}
$$

Some works have shown the variation of the exergy inside a drying chamber during drying time, as illustrated in Figure 14 and Figure 15.

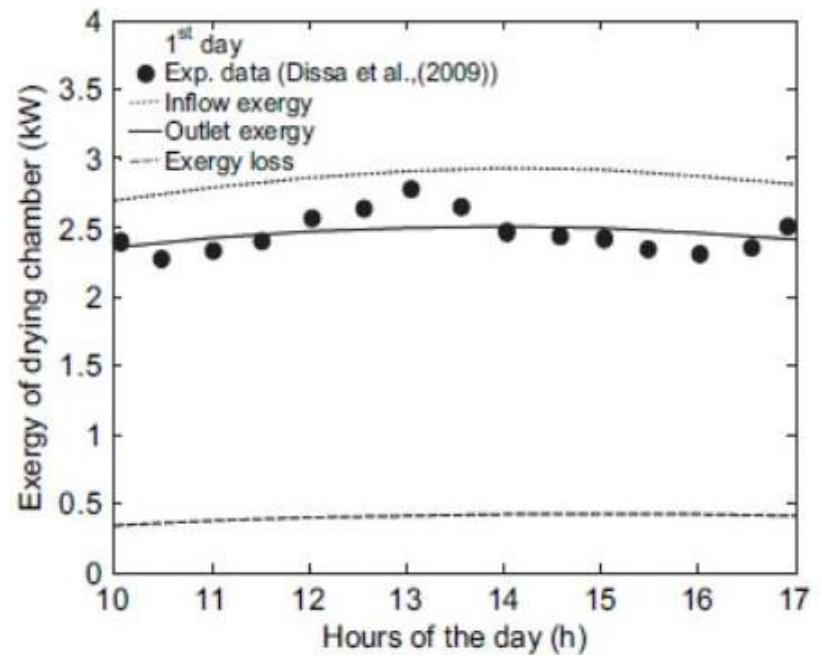

Figure 14. Variation of the drying chamber exergy as a function of the drying time[59]

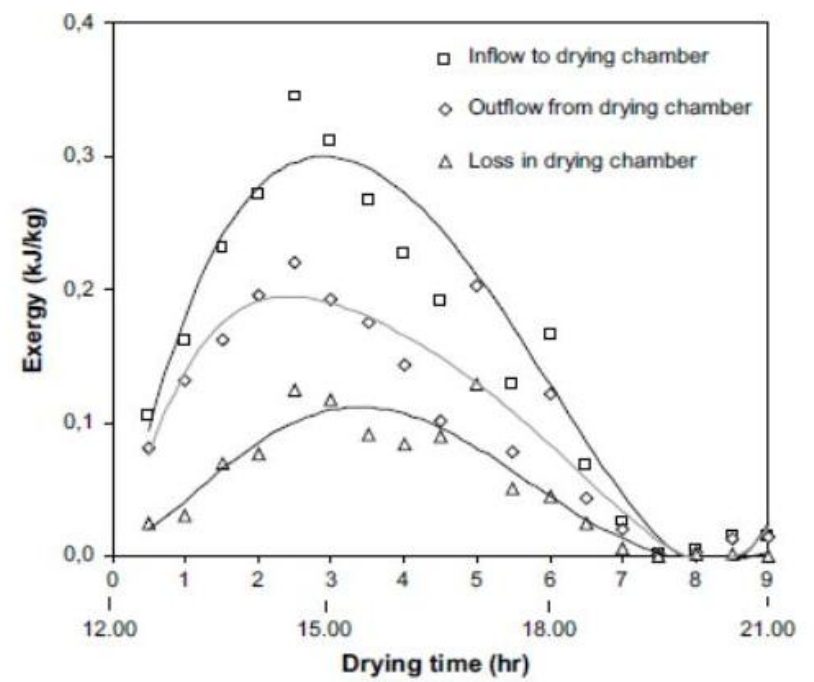

Figure 15. Variation of different exergy parameters inside the drying chamber[58]

This mathematical approach can be used to study thin or packed bed drying with a media supposed as porous [56, 62]. 


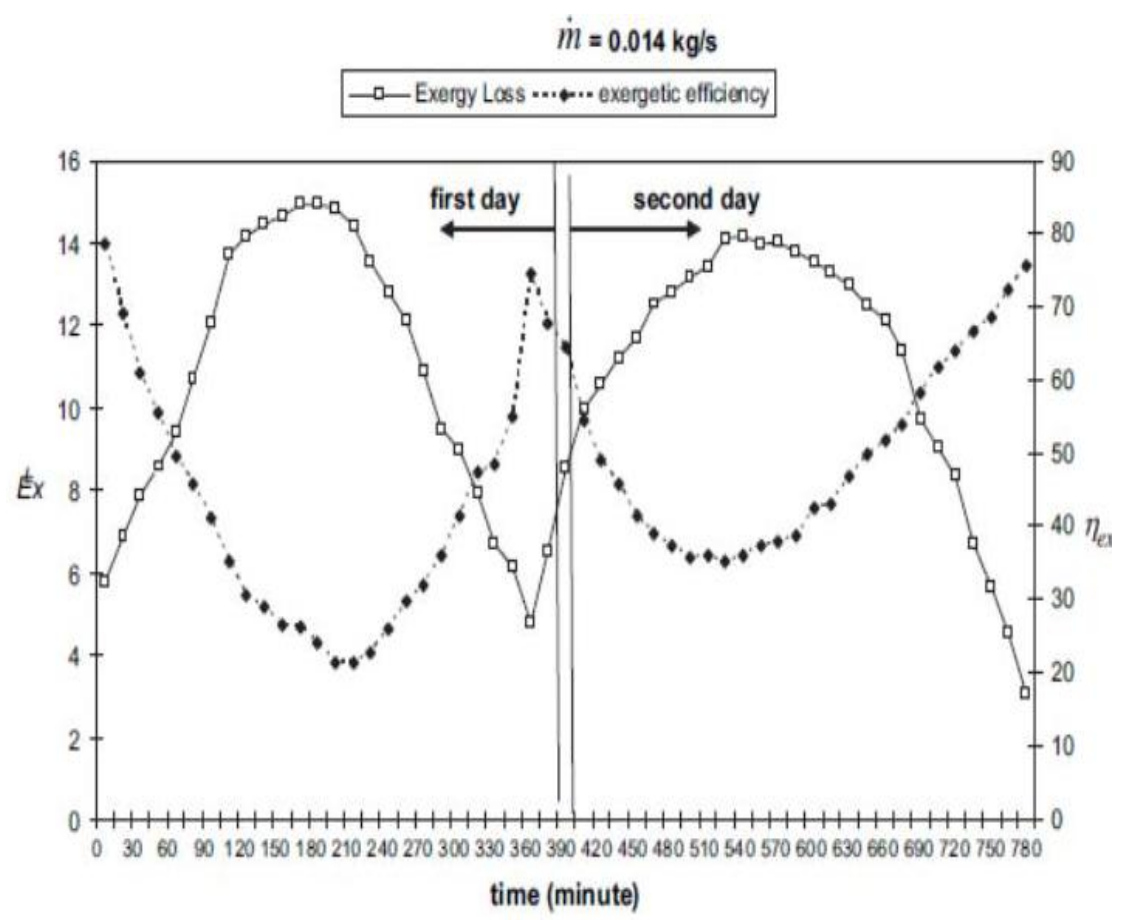

Figure 16. Variation of total exergy loss and total exergetic efficiency of a solar dryer[63]

\subsection{Calculation of the System Exergy Efficiency}

It is determined by:

Exergetic efficiency $=1$-Exergy loss/Exergy input (39)

Where exergy loss and exergy input can be easily calculated using similar equations to equation 25 and equation 26 with adaptation to the solar drying system.

It is important to mention that in some specific cases for transparent walls of a solar dryer, there are radiations received by both the drying chamber and the solar collector then if the surface of the dryer is equal to the surface of the collector; the total exergy of radiation received by the system is double of the quantity presented by equation 27[49].

Total energy loss and exergetic efficiency of a solar dryer are presented in Figure 16.

\section{Conclusions}

Simulation and mathematical modelling plays an important role for the design of a solar drying system. To have an idea about the general behaviour of a solar drying system and to be able to calculate its energetic efficiency; it is important to establish heat and mass balance. This method is then applied for the different components of the drying system, which means both the solar collector and the drying chamber. It allows following the variation, in time and space, of different temperatures and parameters in particular temperature and humidity of the dried product and the heated air, necessary for the calculation of the energetic efficiency. For thick layers drying, the drying chamber is considered as a porous media and then mathematical treatment by using transfers in porous media can be done. Also, this method gives the variations of the air and product temperatures and humidity, permitting the calculation of the energetic efficiency for this case, too.

A detailed mathematical procedure to be adopted for calculation of the exergetic efficiency is proposed with application to a solar collector, to the drying cha mber and the overall solar drying system. This mathematical procedure can be applied for both thin and thick layers. Exergetic efficiency can then be easily calculated by knowing some accessible parameters such as temperatures and humidity.

By means of the presented results, it is clear that the calculated efficiencies are deeply influenced by several parameters such as the variation of the received radiation, the external temperature and the wind velocity during drying time, by internal parameters and the design such as the surface of the solar collector, by the characteristics of the dried product. So, an optimum exploitation of the studied system with a minimum of expenses passes through simulating and modelling, in particular with calculation of energetic and exergetic efficiencies.

\section{Nomenclature}

$\mathrm{Cp} \rightarrow$ specific heat $(\mathrm{J} / \mathrm{kg} . \mathrm{K})$

$\dot{\mathrm{m}} \rightarrow$ mass flow rate $(\mathrm{kg} / \mathrm{s})$

$\mathrm{T} \rightarrow$ temperature $(\mathrm{K})$

$\mathrm{t} \rightarrow$ time $(\mathrm{s})$

\section{Section 2}

$\mathrm{A} \rightarrow$ surface of the collector $\left(\mathrm{m}^{2}\right)$

$\mathrm{F}_{\mathrm{R}} \rightarrow$ heat removal factor of solar collector

$\mathrm{F}^{\prime} \rightarrow$ collector efficiency factor

$\mathrm{h} \rightarrow$ coeffic ient of heat transfer by convection $\left(\mathrm{W} / \mathrm{m}^{2} . \mathrm{K}\right)$

$\mathrm{hr} \rightarrow$ adapted radiative exchange coefficient $\left(\mathrm{W} / \mathrm{m}^{2} . \mathrm{K}\right)$ 


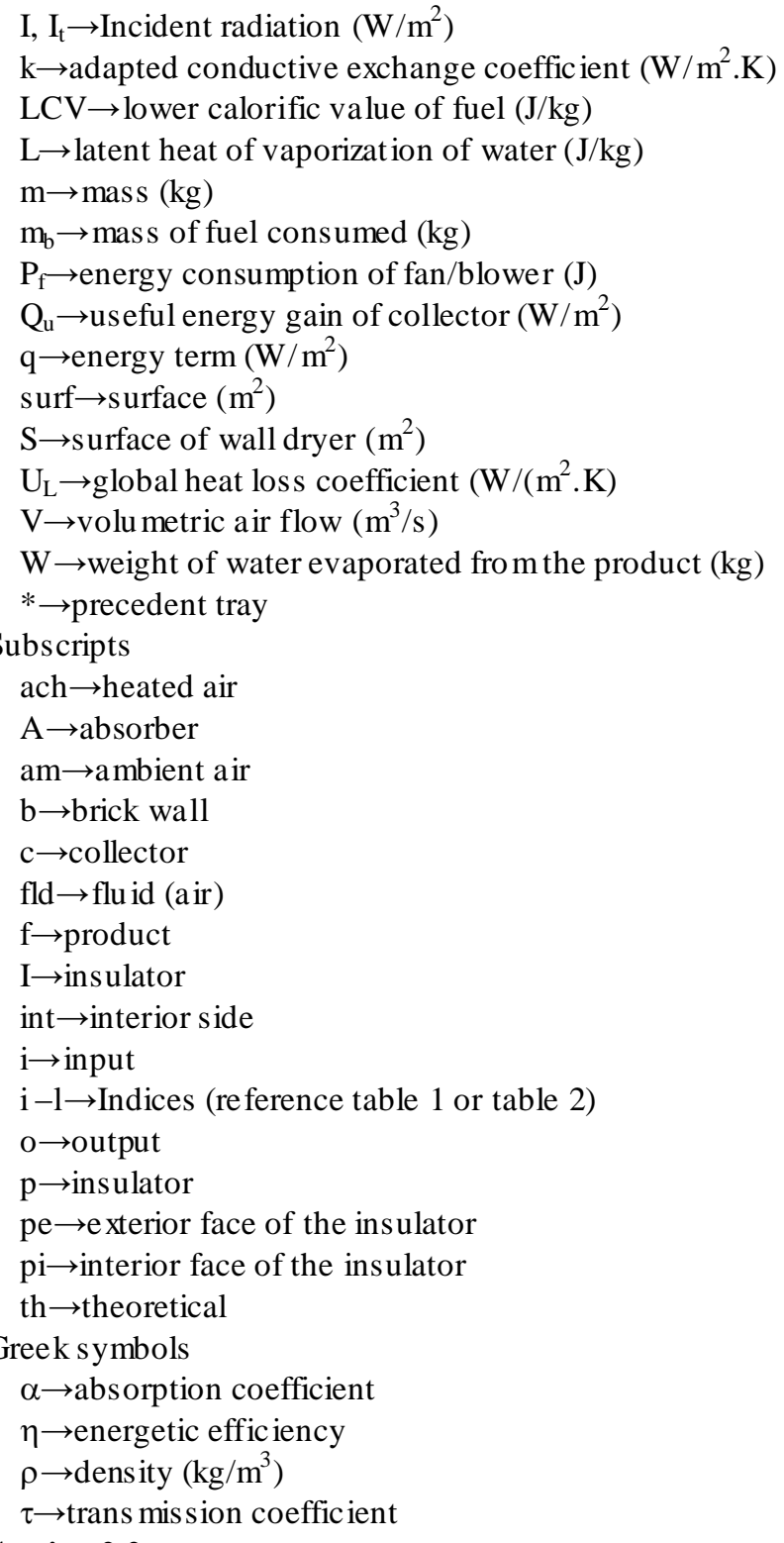

\section{Section 2.2}

$\mathrm{A} \rightarrow$ surface of contact air-product $\left(\mathrm{m}^{2}\right)$

$\mathrm{C} \rightarrow$ mo is ture content of the product $(\mathrm{kg} / \mathrm{kg})$

$\mathrm{D} \rightarrow$ coefficient of diffusion $\left(\mathrm{m}^{2} / \mathrm{s}\right)$

$\mathrm{H} \rightarrow$ latent heat of vaporization of water $(\mathrm{J} / \mathrm{kg})$

$\mathrm{V} \rightarrow$ velocity $(\mathrm{m} / \mathrm{s})$

$\mathrm{w} \rightarrow$ hu mid ity ratio $(\mathrm{kg} / \mathrm{kg})$

$\mathrm{y} \rightarrow$ coordinate $(\mathrm{m})$

Subscripts

eff $\rightarrow$ effective

$\mathrm{f} \rightarrow$ fluid

$\mathrm{s} \rightarrow$ solid (dried product)

Greek symbols

$\varepsilon \rightarrow$ bed porosity

$\sigma \rightarrow$ mass transfer factor $\left(\mathrm{kg} / \mathrm{m}^{3} \mathrm{~s}\right)$

\section{Section 3}

$$
\begin{aligned}
& \mathrm{A}_{\mathrm{i}} \rightarrow \text { inlet area }\left(\mathrm{m}^{2}\right) \\
& \mathrm{E}_{\mathrm{i}} \rightarrow \text { emissive power at in let }\left(\mathrm{W} / \mathrm{m}^{2}\right) \\
& \mathrm{Ex} \rightarrow \text { exergy }(\mathrm{J}) \\
& \dot{\mathrm{E}} \rightarrow \text { rate of energy flow }
\end{aligned}
$$

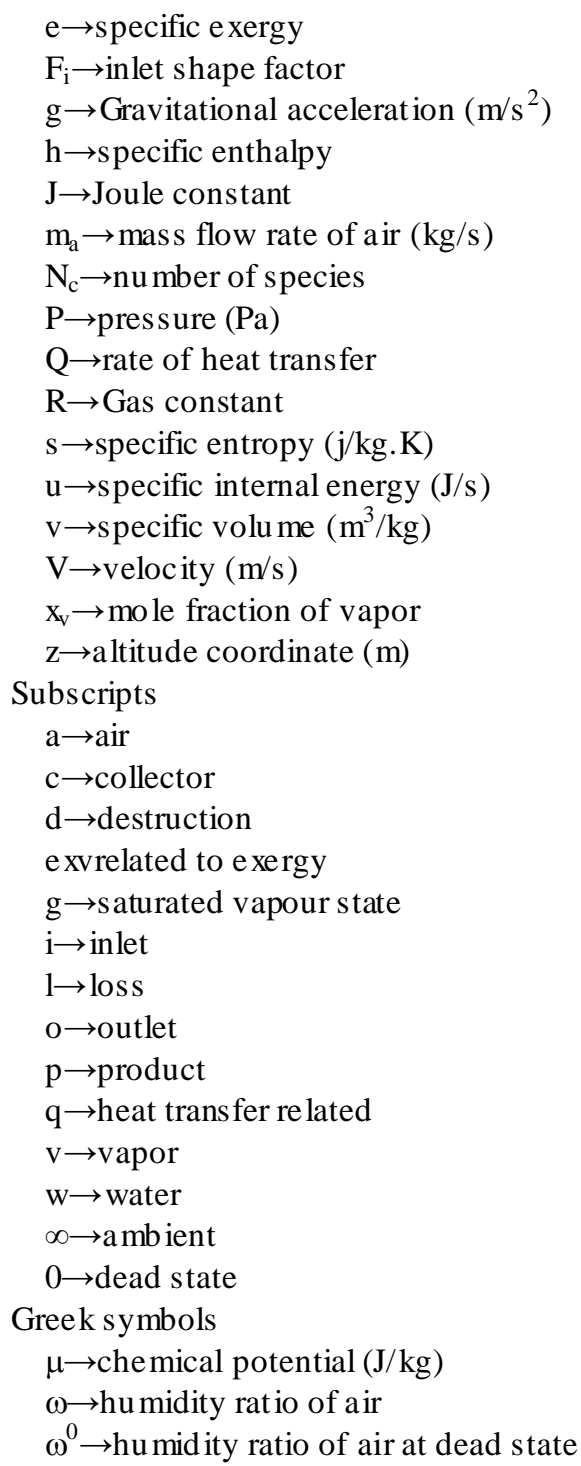

\section{REFERENCES}

[1] Bennamoun, L., Belhamri, A., 2003, Design and simulation of a solar dryer for agriculture products, Journal of Food Engineering, 59 (2-3), 259-266.

[2] Gallali, Y. M., Abujnah, Y.S., Bannani F. K., 2000, Preservation of fruits and vegetables using solar drier: a comparative study of natural and solar drying III; chemical analysis and sensory evaluation data of the dried samples (grapes, figs, tomatoes and onions), Renewable Energy, 19(1-2), 203-212.

[3] Srivastava, V. K., John, J., 2002, Deep bed drying modeling, Energy Conversion \& Management, 43 (13), 1689-1708.

[4] Arnaud, G., Fohr, J. P., 1988, Slow drying simulation in thick layers of granular products, International Journal of Heat and Mass Transfer, 31 (12), 2517-2526.

[5] Bennamoun, L., Belhamri, A., Ali-Mohamed, A., 2009, Application of a diffusion to predict drying kinetics changes under variable conditions: Experimental and simulation study, 
Fluid Dynamics \& Materials Processing, 5(2), 177-191.

[6] Chen, P., Pei, D. C. T., 1989, A mathematical model of dry ing processes, International Journal of Heat and Mass Transfer, 32 (2), 297-310.

[7] Huang, C. L. D., Siang, H. H., Best C. H., 1979, Heat and moisture transfer in concrete slabs, International Journal of Heat and Mass Transfer, 22 (2), 257-266.

[8] Bennamoun, L., 2012, Solar drying of wastewater sludge: A review, Renewable and Sustainable Energy Reviews, 16 (1), 1061-1073.

[9] Keey, R. B., 1992, Dry ing of loose and particulate materials, Hemisphere Publishing Corporation, U.S.A.

[10] Mujumdar, A. S., 2006, Principles, classification, and selection of dryers, Handbook of industrial drying, Mujumdar A.S., Ed. U.S.A: CRC press.

[11] Bennamoun, L., 2011, Reviewing the experience of solar drying in Algeria with presentation of the different aspects of solar dryers, Renewable and Sustainable Energy Reviews, 15 (7), 3371-3379.

[12] Eckchukwu, O. V., Norton, B., 1999, Review of solr-energy drying systems II: an overview of solar drying technology, Energy Conversion \& Management, 40 (6), 615-655.

[13] Daguenet, M., 1985, Les séchoirs solaires: théorie et pratique, UNESCO, Paris.

[14] Boughali, S., Benmoussa, H., Bouchekima, B., Mennouche, D., Bouguettaia, H., Bechki, D., 2009, Crop drying by indirect active hybrid solar-Electrical dryer in the eastern Algerian Septentrional Sahara, Solar Energy, 83 (12), 2223-2232.

[15] Jain, D., 2007, Modeling the performance of the reversed absorber with packed bed thermal storage natural convection solar crop dryer, Journal of Food Engineering, 78 (2), 637-647.

[16] Jain, D., Jain, R. K., 2004, Performance evaluation of an inclined multi-pass solar air heater with in-built thermal storage on deep-bed drying application, Journal of Food Engineering, 65 (4), 497-509.

[17] Chauhan, P. M., Choudhury, C., Garg, H. P., 1996, Comparative performance of coriander dry er coupled to solar air heater and solar air-heater-cum-rockbed storage, Applied Thermal En gineering, 16 (6), 475-486.

[18] Mohanraj, M., Chandrasekar, P., 2009, Performance of a forced convection solar drier intergrated with gravel as heat storage material for chilli drying, Journal of Engineering Science and Technology, 4 (3), 305-314.

[19] Shanmugam, V., Natarajan, E., 2006, Experimental investigation of forced convection and desiccant integrated solar dryer, Renewable Energy, 31 (8), 1239-1251.

[20] Luna, D., Nadeau, J. P., Jannot, Y., 2010, Model and simulation of a solar kiln with energy storage, Renewable Energy, 35 (11), 2533-2542.

[21] Devahastin, S., Pitaksuriy arat, S., 2006, Use of latent heat storage to converse energy during drying and its effect on drying kinetics of a food product, Applied Thermal Engineering, 26(14-15), 1705-1713.
[22] Bal, L. M., Sudhakar, P., Satya, S., Naik, S. N., 2009, Solar dry er with latent heat storage systems for drying agricultural food products, in Proceedings of International Conference of Food Security and Environmental Sustainability.

[23] Al-Hamadani, A. A. F., Shukla, S. K., 2011, Water Distillation using solar energy system with lauric acid as storage medium, International Journal of Energy Engineering, $1(1), 1-8$.

[24] Tripathy, P. P., Kumar, S., 2009, A methodology for determination of temperature dependent mass transfer coefficients from drying kinetics: Application to solar drying, Journal of Food Engineering, 90 (2), 212-218.

[25] Boubekri, A., Benmoussa, H., Mennouche, D., 2009, Solar drying kinetics of date palm fruits assuming a step-wise air temperature change, Journal of Engineering Science and Technology, 4 (3), 292-304.

[26] Doymaz, I., 2005, Sun drying of figs: an experimental study, Journal of Food Engineering, 71 (4), 403-407.

[27] Toğrul, I. T., Pehlivan, D., 2004, Modelling of thin layer drying kinetics of some fruits under open-air sun drying process, Journal of Food Engineering, 65 (3), 413-425.

[28] Toğrul, I. T., Pehlivan, D., 2003, Modelling of dry ing kinetics of some single apricot, Journal of Food Engineering, 58 (1), 23-32.

[29] Midilli, A., Kucuk, H., Yapar, Z., 2002, A new model for single-layer drying, Drying technology, 20 (7), 1503-1513.

[30] El Sebaii, A. A., Aboul-Enein, S., Ramadan, M. R. I., El-Gohary, H. G., 2002, Empirical correlations for drying kinetics of some fruits and vegetables, Energy, 27 (9), 845-859.

[31] Toğrul, I. T., Pehlivan, D., 2003, Mathematical modelling of solar drying of apricots in thin layers, Journal of Food Engineering, 55 (3), 209-216.

[32] Yaldiz, O., Ertekin, C., Uzun, H. I., 2001, Mathematical modeling of thin layer solar drying of sultana grapes, Energy, 26 (5), 457-465.

[33] Karathanos, V. T., Belessiotis, V. G., 1997, Sun and artificial air drying kinetics of some agricultural products, Journal of Food Engineering, 31 (1), 35-46.

[34] Kooli, S., Fadhel, A., Farhat, A., Belghith, A., 2007, Drying of red pepper in open sun and greenhouse conditions. Mathematical modeling and experimental validation, Journal of Food Engineering, 79 (3), 1094-1103.

[35] Bennamoun, L., Belhamri, A., 2006, Numerical simulation of drying under variable external conditions: Application to solar dry ing of seedless grapes, Journal of Food en gin eering, 76 (2), 179-187.

[36] Dincer, I., 2011, Exergy as a potential tool for sustainable dry ing sy stems, Sustainable Cities and Society, 1 (2), 91-96.

[37] Peinado, D., de Vega, M., Garcia-Hernando, N., Marugán-Cruz, C., 2011, Energy and exergy analysis in an asphalt plant's rotary dryer, Applied Thermal En gineering, 31 (6-7), 1039-1049.

[38] Catton, W., Carrington, G., Sun, Z., 2011, Exergy analy sis of an isothermal heat pump dryer, Energy, 36 (8), 4616-4624. 
[39] Karamarkovic, R., Karamarkovic, V., 2010, Energy and exergy of biomass dasification at different temperatures, Energy, 35 (2), 537-549.

[40] Nwosu, N.P., 2009, Employing exergy-optimized pin fins in the design of an absorber in a solar air heater, Applied Solar Energy, 45 (4), 248-253.

[41] Liu, Y., Zhao, Y., Feng, X., 2008, Exergy analysis for a freeze-dry ing process, Applied Thermal Engineering, 28 (7), 675-690.

[42] Liapis, A. I., Bruttini, R., 2008, Exergy analysis of freeze drying of pharmaceuticals in vials on trays, International Journal of Heat and Mass Transfer, 51 (15-16), 3854-3868.

[43] Akpinar, E. K., Midilli, A., Bicer, Y., 2005, Energy and exergy of potato drying process via cyclone type dryer, Energy Conversion \& Management, 46 (15-16), 2530-2552.

[44] Holmberg, H., Ahtila, P., 2005, Evaluation of energy efficiency in biofuel drying by means of energy and exergy analyses, Applied Thermal Engineering, 25 (17-18), 3115-3128.

[45] Bennamoun, L., Belhamri, A., 2011, Study of solar thermal energy in the north region of Algeria with simulation and modeling of an indirect convective solar drying system, Nature and Technology, 4, 34-40.

[46] Gbaha, P., Yabouet Andoh, H., Kouassi Saraka, J., Kaménan Koua, B., Touré, S., 2007, Experimental investigation of a solar dryer with natural convective heat flow, Renewable Energy, 32 (11), 1817-1829.

[47] Tiris, C., Ozbalta, N., 1995, Thermal performance of a new solar air heater, International Communications in Heat and Mass Transfer, 22 (3), 411-423.

[48] Boulemtafes-Boukadoum, A., Benzaoui, A., 2011,Energy and exergy analysis od solar drying process of mint, Energy Procedia, 6, 583-591.

[49] Chowdhury, M. M. I., Bala, B. K., Haque, M. A., 2011 Energy and exergy analysis of the solar drying of jackfruit leather, Biosy stems Engineering, 110 (2), 222-229.

[50] Youcef-Ali, S., Moummi, N., Desmons, A., Abene, A., Messaoudi, H., Le Ray, M., 2001, Numerical and experimental study odf dryer in forced convection, International Journal of Energy Research, 25(), 537-553.

[51] Bennamoun, L., Belhamri, A., 2008, Mathematical description of heat and mass transfer during deep bed drying: Effect of product shrinkage on bed porosity, Applied Thermal
Engineering, 28 (17-18), 2236-2244.

[52] Augustus Leon M., Kumar, S., Bhattacharya, S. C., 2002, A comprehensive procedure for performance evaluation of solar food dryers, Renewable and Sustainable Energy Reviews, 6 (4), 367-393

[53] Tiris, C., Tiris, M., Dincer, I., 1995, Investigation of the thermal efficiencies of solar dryer, energy Conversion and Management, 36 (3), 205-212.

[54] Bennamoun, L., Belhamri, A., 2008, Study of heat and mass transfer in porous media: Apllication to packed bed drying, Fluid Dynamics and Materials Processing, 4 (4), 221-230.

[55] Kanoglua, M., Dincer, I., Rosen M., A., 2007, Understanding energy ad exergy efficiencies for improved energy management in power plant, Energy Policy, 35 (7), 3967-3978.

[56] Prommas, R., Rattanadecho, P., Cholaseuk, D., 2010, Energy and exergy analyses in dry ing process of porous media using hot air, Internatinal Communications in heat and Mass Transfer, 37 (4), 372-378.

[57] Midilli, A., Kucuk, H., 2003, Energy and exergy analy ses of solar dry ing process of pistachio, Energy, 28 (6), 539-556.

[58] Celma, A. R., Cuadros, F., 2009, Energy and exergy of OMW solar dry ing process, Renewable Energy, 34 (3), 660-666.

[59] Sami, S., Etesami, N., Rahimi, A., 2011, Energy and exergy analysis of an indirect solar cabinet dryer based on mathematical modeling results, Energy, 36 (5), 2847-2855.

[60] Dincer, I., Rosen, M. A., 2007, Exergy, Environment and Sustainable Development, analysis of drying processes systems, Elsevier.

[61] Dincer, I., Shahin, A.Z., 2004, A new model for thermodynamic analysis of a drying process, International Journal of Heat and Mass Transfer, 47 (4), 645-652.

[62] Prommas, R., Keangin, P., Rattanadecho, P., 2010, Energy and exergy analyses in convective drying process of multi-layered porous packed bed, International Communications in Heat and Mass Transfer, 37 (8), 1106-1114.

[63] Akbulut, A., Durmuş A., 2010, Energy and exergy analy ses of thin dry ing of mulberry in a forced solar dry er, En ergy, 35 (4), 1754-1763. 